\title{
A RELEITURA DE PORTFÓLIOS PARA A CONSTRUÇÃO DO TRABALHO DE CONCLUSÃO DE CURSO DE PEDAGOGIA
}

\author{
Cláudia Queiroz Miranda* \\ Benigna M aria de Freitas Villas Boas*
}

RESU M 0: 0 texto apresenta resultados da pesquisa que teve como objetivo geral analisar o processo de releitura de portfólios com vistas à construção do Trabalho de Conclusão de Curso (TCC) de Pedagogia. Participaram da investigação seis professores-alunos egressos e uma professora-mediadora do curso de Pedagogia para professores em exercício no início de escolarização (PIE). 0 curso foi oferecido pela Faculdade de Educação da un B em convênio com a Secretaria de Estado de Educação do D istrito Federal. Analisam-se os procedimentos utilizados por professores-alunos egressos para a releitura de portfólios e os procedimentos adotados pela professora-mediadora para a orientação desse processo, assim como as dificuldades e contribuições oferecidas por esta releitura para a construção do Tcc. O bservou-se que o processo de releitura abriu espaço para o desenvolvimento metacognitivo: reconsideraram-se as práticas avaliativas; criaram-se espaços de diferenciação pedagógica; a reflexão foi enfatizada.

Palavras chave: Trabalho de Conclusão de Curso. Avaliação. Formação de professores.

\section{A NEW LOOK AT PORTFOLIOS IN CONSTRUCTING THE PEDAGOGY COURSE FINAL PAPER}

ABST RACT: This article presents the results of a research that analyzed the process of analyzing portfolios in a different way to construct the Pedagogy C ourse Final Paper. Six newly graduated

* M estre em Educação e professora da Secretaria de Estado de Educação do D istrito Federal. E-mail: webclaudia33@gmail.com

** D outora em Educação e professora do Programa de Pós-G raduação em Educação da U niversidade de Brasília (UNB).E-mail: mbboas@terra.com.br

Educ. Soc., Campinas, vol. 28, n. 29, n. 102, p. 215-229, jan./abr. 2008 
student-teachers and teacher-mediator perceptions are discussed. The course was offered by the Education College at the U niversity of Brasilia and the local Educational Bureau to in-service teachers who worked in public elementary schools with grades one to four. The article analyses the procedures used by the student-teachers to analyze portfolios and the procedures used by the teacher-mediator to guide them in this process; as well as the difficulties and contributions that were observed. It could be observed that the process made room for the development of metacognition: assessment practices were reconsidered; opportunities for pedagogical differentiation were created; reflection was emphasized.

Key words: Final course paper. Assessment. Teacher education.

\section{Contextualizando o tema}

E

ste texto apresenta resultados da pesquisa que teve como objetivo geral analisar o processo de releitura de portfólios com vistas à construção do Trabalho de Conclusão de Curso (TCC) de Pedagogia. Participaram da investigação professores-alunos egressos e uma professora-mediadora do Curso de Pedagogia para professores em exercício no início de escolarização (PIE). 0 curso contou com 55 mediadores, que eram professores da Secretaria de Estado de Educação do D istrito Federal, selecionados para serem os docentes do mesmo. Esses mediadores possuíam habilitação em nível superior, freqüentaram curso de especialização oferecido pela Faculdade de Educação da Universidade de Braślia (UNB) e recebiam orientação dos tutores, que eram professores doutores da mesma faculdade.

D iscutem-se os achados referentes aos seguintes objetivos específicos: analisar os procedimentos utilizados por professores-alunos egressos para a releitura de portfólios e os procedimentos adotados pela professoramediadora para a orientação desse processo; identificar e analisar as dificuldades e contribuições oferecidas pela releitura de portfólios para a construção do Tcc. 0 curso em questão foi oferecido de 2001 a junho de 2006 pela Faculdade de Educação da un B por meio de convênio firmado com a Secretaria do Estado de Educação do Distrito Federal (SEEDF). Teve como finalidade oferecer formação em nível superior para professores das escolas públicas do D istrito Federal de 1ạ a 4ạ séries da educação fundamental, educação de jovens e adultos, educação infantil e educação especial. 
A pesquisa cujos resultados são apresentados realizou-se no ano de 2005, por meio da abordagem qualitativa. D ela participaram uma professora-mediadora e seis professores-alunos da turma com a qual ela trabalhou durante o processo de construção do Tcc. Como procedimentos de coleta de dados, foram usadas entrevista e análise do Caderno de 0 rientação para a Construção do Tcc, elaborado pelo grupo de professoresmediadores, dos portfólios, dos Tcc e do caderno de registro da professora-mediadora.

Com 0 objetivo de tornar esse trabal ho coerente com o discurso elaborado durante toda a formação proporcionada pelo curso e para dar unidade ao processo de releitura que seria desencadeado, o grupo de professores-mediadores formul ou a seguinte pergunta geradora das reflexões e das atividades: Como compreendo a minha prática pedagógica como sujeito em formação?

\section{Compreendendo o processo avaliativo no PIE}

0 fato de os cursistas serem professores-alunos conduziu a duas decisões: adoção da avaliação formativa e uso do portfólio como o principal procedimento de avaliação.

0 curso desenvolveu-se em forma de módulos de trabalho. Para cada módulo o professor-aluno construiu um portfólio. 0 início da construção de cada um deles se dava com a formulação de propósitos e descritores de avaliação. Elaboravam-se propósitos comuns a todas as turmas do curso e cada professor-aluno definia seus propósitos individuais. Ampliava-se, assim, o seu espaço de autonomia intelectual. Com eles em mãos, as turmas discutiam as necessidades individuais e grupais. D urante os encontros de sala de aula debatiam-se formas de colocar em prática os propósitos do portfólio. A presentavam-se questões para análise e as reflexões pessoais de cada um. À medida que as atividades eram registradas no portfólio, os professores-alunos as apresentavam aos seus colegas de sala e ao professor-mediador, para que pudesse ser acompanhada a processualidade de suas reflexões e para que todo o grupo se beneficiasse disso. 0 portfólio consistiu no registro das evidências de aprendizagem dos professores-alunos, por eles selecionadas, em atendimento aos propósitos comuns e aos específicos, assim como aos descritores de avaliação. 
0 portfólio consistiu no principal procedimento de avaliação da aprendizagem dos professores-alunos por nortear-se pelos princípios da reflexão, criatividade, parceria, auto-avaliação e autonomia. Acostumados ao trabal ho pedagógico em que os alunos geralmente reproduzem idéias e têm poucas chances de escrever, os professores-alunos estranharam, no início, o trabalho com o portfólio. Com o passar do tempo essa nova dinâmica foi compreendida e o portfólio ganhou importância, passando a ser 0 eixo organizador do trabalho pedagógico do curso (Villas Boas, 2004).

\section{Compreenden do o processo de releitura de portfólios}

A un B tem incluído nos currículos de seus cursos o tcc que, como o nome indica, costuma ser desenvolvido durante 0 último semestre do curso. 0 artigo 8o do Parecer CNE/CP n. 5, de 13 de dezembro de 2005, que trata das D iretrizes Curriculares $N$ acionais para o Curso de Pedagogia, estabelece que, "nos termos do projeto pedagógico da instituição, a integralização de estudos será efetivada por meio de (...) atividades complementares envolvendo o planejamento e o desenvolvimento progressivo do Trabalho de Curso, atividades de monitoria, de iniciação científica e de extensão (...)". O bserve-se que: a) substituiu-se "Trabalho de Conclusão de Curso", denominação usada na unB, por "Trabalho de Curso"; e b) introduziu-se "o planejamento e o desenvolvimento progressivo" do Trabalho de Curso. Esse componente curricular ganha importância, ao perder a característica de atividade final do curso e passar a ser planejado e desenvolvido ao longo do mesmo. No curso de Pedagogia regularmente oferecido pela UNB, foi adotada por muito tempo a monografia como atividade de final de curso. 0 PIE é que inovou ao criar o TCC com base na releitura dos portfólios. Por quê? A construção do portfólio evidenciou sua importância no processo avaliativo e na condução das atividades do curso como um todo. A sua utilização promovia reflexões sobre aspectos do trabalho pedagógico do curso e sobre o desenvolvido nas escolas em que os professores-alunos atuavam. Todo o grupo passou a entender que o portfólio, como procedimento avaliativo da aprendizagem dos professores-alunos, no curso, não poderia se distanciar de um trabalho que se define como de conclusão de curso. Percebeu-se, então, que para o TCc era necessário que o professor-aluno revisitasse seus registros pessoais para rever sua trajetória de aprendizagem e de formação, a 
confrontasse com suas percepções ao final do curso e analisasse a sua intervenção no processo formativo do qual fazia parte.

Essa maneira de gerar a construção do TCc é uma proposta inovadora no âmbito da formação de professores, porque abrange os processos avaliativos e não apenas os conteúdos. Produz um espaço para compreender o professor-aluno como pesquisador, pois "a pesquisa, não sendo um fim em si mesma, pode ser a conseqüência de um fazer em que 0 indivíduo faz e coloca questões" (Esteban \& Zaccur, 2002, p. 15).

0 portfólio no PIE instaurou formas de registros pessoais e processuais sobre evidências da formação e sobre a forma como os professoresalunos realizavam a leitura de mundo. Esses registros tornaram-se históricos e eram revisitados sempre que necessário. 0 Tcc assumiu, então, a forma de releitura do processo formativo do aluno, por meio do portfólio. Assim, destaca-se que

0 Tcc marca a culminância dos trabal hos realizados desde o início do curso, caracterizando-se como um modo possível de efetivar uma releitura do processo deformação do professor-aluno. É um trabalho organizado pedagogicamente, que explicita a transversalidade da proposta pedagógica do $\mathrm{PIE}$, tendo como referência sua organização curricular por áreas e eixos integradores. (UNB, 2003, p. 17)

O TCC no curso PIE, por meio da releitura de portfólios, pretendeu ser uma síntese possível das transformações ocorridas ao longo do processo formativo do professor-aluno e, ainda, proporcionar a ressignificação do sentido de sua formação. Ele precisava refletir as histórias que professores-alunos e professores-mediadores construíram ao elaborarem a trajetória de releitura, ao ler, refletir, rever, situar e/ou orientar a produção. M esmo porque foi uma forma nova de criar o elo entre o trabalho pedagógico realizado durante o curso e o produto que dele resultou. $\mathrm{O}$ s objetivos do TCC no curso PIE foram os seguintes:

(...) possibilitar a releitura sobre as construções vivenciadas na realização do curso, das atividades acordadas e dos registros materiais que se organizaram nos portfólios durante o processo de formação do professor-aluno; desenvolver, por meio de reflexão e crítica, oportunidades para que os alunos se reconheçam como participantes e co-responsáveis na construção do conhecimento e na transformação da realidade; desvel ar constantemente a real idade para ultrapassar o senso comum, intervir, aprender; evidenciar, em 
forma de registro, a transversalidade da proposta curricular do curso, constituindo-se no trabal ho de conclusão do curso. (un B, 2003, p. 19)

\section{Associando o processo de releitura à metacognição}

0 processo de releitura dos portfólios abriu espaço para o desenvolvimento metacognitivo. A palavra metacognição é composta por meta e cognição. M eta, de origem grega (metá), significa "reflexão crítica sobre" (Ferreira, 1999, p. 1325). A cognição, em termos restritos, se refere a um tipo específico de representação dos objetos e fatos e, num sentido lato, a qualquer tipo de representação da informação proveniente do meio. A metacognição diz respeito ao conhecimento do próprio conhecimento, à avaliação, à regulação e à organização dos próprios processos cognitivos. Significa ir além da cognição; é a faculdade de conhecer o próprio ato de conhecer, ou, por outras palavras, tomar consciência, analisar e avaliar como se conhece (Ribeiro, 2003).

Constituem vantagens da aprendizagem orientada pela metacognição: a) o desenvolvimento da auto-apreciação e do autocontrole cognitivos como formas de pensamento que o sujeito pode desenvolver e que lhe permitem ter papel ativo e construtivo no seu próprio conhecimento; b) a abertura de novas perspectivas para o estudo das diferenças individuais no desempenho escolar, devido à forma de atuação de cada aluno sobre os seus próprios processos de aprendizagem. A metacognição, apesar de ser dependente do desenvolvimento cognitivo, favorece e é motor do próprio desenvolvimento, por permitir ao sujeito ir mais longe no seu nível de realização (idem, ibid.).

A mesma autora (idem, ibid.) ensina que a eficácia da aprendizagem não depende apenas da idade, da experiência e do nível intelectual, mas, também, da aquisição de estratégias cognitivas e metacognitivas que possibilitem ao aluno planejar e monitorar o seu desempenho escolar. Para aprender é preciso aprender como fazer para aprender; não basta fazer e saber, é preciso saber como se faz para saber e como se faz para fazer. A metacognição é uma capacidade-chave para a aprendizagem, possibilitando aprender a aprender, o que não costuma ser valorizado pela escola.

A análise das contribuições da metacognição indica que a escola não se limita a ser apenas espaço de difusão de saberes, mas apresenta-se "como um contexto que estimule os seus alunos a apropriar-se e a construir, de 
uma forma progressiva, o seu patrimônio pessoal de metaconhecimentos, ou seja, de conhecimentos sobre o modo como se adquire, gere, utiliza e alarga o seu campo de saberes" (Cosme \& Trindade, 2001, apud Ribeiro, 2003, p. 114).

Levando-se em conta os princípios norteadores da construção do portfólio, já mencionados, percebe-se que este pode ser um dos meios de desenvolvimento da metacognição e que esta, por sua vez, é um apoio ao trabal ho com o portfólio. A releitura de portfólios complementa esse processo. Cabe aos que coordenam essas atividades criar mecanismos para tornar possível essa estreita vinculação nos diversos contextos do trabaIho escolar e não-escolar.

\section{Enfrentando e superando as dificuldades iniciais do processo de releitura de portfólios}

O contato inicial com a idéia de releitura de portfólios provocou algumas dificuldades:

Professor-aluno - No início eu tivemuita dificuldade em fazer a releitura de portfólios. Q uando disseram que eu teria que fazêla, a primeira coisa que lembrei foram os primeiros portfólios que eu fiz. Eu não tinha quase nada, pois os primeiros foram difíceis para compreender o que se queria em um trabalho queeu nunca tinha feito.

Professor-aluno - No início eu briguei muito com essa tal dereleitura, porque, até então, eu não estava compreendendo onde que ela queria chegar. Acho quenem os mediadores sabiam como fazer eno que ia dar.

Professor-aluno - D eixou-se muito para o final para falar sobre a releitura. Foi aquele "baque" não saber o que fazer, pois ninguém conhecia o Tcc e nem sabia real mente o que era releitura.

Professor-aluno - M eu D eus do céu! Vou ter que reler tudo que eu fiz? Foi um pouco de desespero, ansiedade... vocêter queler todo o seu trabalho de novo eem cima dele você ter que produzir outro trabalho!

Professor-aluno - No início fiquei assustado. Eu tenho um problema com coisas do passado. Eu sempreme pergunto: Eu era assim, dessejeito?

Professor-mediador - Aquel einício para a gentenão foi fácil, foi uma coisa! Tínhamos muitos questionamentos: Como vamosidentificar, por meio da rel eitura, o tema? Será que as releituras que eles nos apresentam vieram mesmo dosportfólios deles? 
O bserva-se, por parte dos professores-alunos: desconhecimento sobre o que seria releitura; incômodo em re-olhar as produções; e 0 inacabamento do processo, que estava em construção por todo o grupo. Por parte da professora-mediadora percebe-se a angústia relacionada à identificação do tema do Tcc e a dúvida sobre as releituras. Tudo era muito novo e era grande a expectativa acerca do alcance dos objetivos. O s primeiros passos para a compreensão da releitura dos portfólios foram marcados pela incerteza e pela perplexidade diante da situação de autorizar o professor-aluno a auto-investigar, isto é, produzir uma reflexão sobre a sua própria aprendizagem.

A professora-mediadora revela como se deu o início do processo de releitura:

Eu achava que se eles pudessem ir fazendo a releitura, ampliando o tema e fazendo uso do que estava no módulo v evi era melhor. Era uma forma de ampliar, de descobrir aquilo em que el es avançaram ou as dificuldades que tiveram. Pedi a releitura de um portfólio e cada um foi fazer, bem livre, porque a ansiedade naquel e momento era grande. Eles fizeram e socializaram, para ver se eles se acal mavam um pouco; el es puderam ver as possibilidades dessa releitura de portfólios. Eles social izaram as diferentes formas depois.

0 depoimento de um professor-aluno explica como o grupo foi descobrindo a forma de realizar a releitura:

Eu não tinha consciência do que seria releitura. Com o tempo, fui descobrindo que eu já fazia o re-olhar, uma análise, não com a intenção de produzir o TCC, com o objetivo " $x$ " - vou procurar dados para este fim. Q uando o mediador pediu os primeiros registros de releitura do 10 módulo, fomos enfocando o que tinha sido importante, o que tinha chamado mais a atenção... aí eu realmente pude perceber, ficou mais evidente. $\mathrm{N}$ a turma, cadaum foi falando o jeito que fez.

U ma das dificuldades enfrentadas foi a de que o processo de releitura não seria uma mera identificação de um tema sobre o qual cada professor-aluno iria escrever.

Professor-aluno - A mediadora nem usava a palavra tema para o Tcc. Ela sempre frisava que não era um tema. D izia que a gente tinha que ler 0 portfólio ever aquilo quefoi mais significativo no processo deaprendizagem para que pudéssemos escrever sobre. N o início confundiu um pouco, mas depoisficou fácil. D aí eu precisava me preocupar com o que eu já produzi e já fiz com meus alunos... al go que eu mecomprometi equetinha vivido. 
Professor-aluno - Q uando disseram que não teria tema, todo mundo ficou perdido, pois se não tem tema ia escrever sobre o quê? A orientação era que não se preocupasse com o tema. $\mathrm{N}$ ão tinha um tema específico a princípio... aí eu fui em cada portfólio. Q uando eu vi, meu Tcc já estava praticamente pronto dentro do meu portfólio, porquejá tinha todos os meus registros e 0 que eu fazia para sanar as minhas dificuldades. Estava tudo ali registrado!

Professora-mediadora - 0 conflito sobre o tema eu resolvi, discutindo lá no grupo. Foi com a fala da "........" que dizia que o importante no pie écomo chegar ao tema. I sso éo central! Se o aluno ol ha a pergunta geradora, se faz a rel eitura do portfólio, ele vai chegar a um tema, porém a grandequestão é como isso surge. E o que esse tema tem a ver com o sujeito e com a sua trajetória.

O s depoimentos evidenciam que os princípios norteadores da construção do portfólio (reflexão, criatividade, auto-avaliação, parceria e autonomia) continuaram presentes na elaboração do trabalho final do curso. O s registros no portfólio foram objeto de reflexão sobre os saberes produzidos não apenas teoricamente, mas, também, por sua ação diante dos desafios cotidianos, transformando o seu meio e a si mesmos. A releitura de portfólios possibilitou a identificação dos saberes produzidos e a sua ampliação.

A pergunta geradora do Tcc (Como compreendo a minha prática pedagógica como sujeito em formação?) foi fecunda para criação de caminhos a serem trilhados pela professora-mediadora:

Q uando nós começamos com isso: 0 queé releitura? Foi bem amplo, a partir daquilo que todo mundo tem e todo mundo faz para chegar à diferença de releitura no curso PIE. A gente conversava bastanteno PIE e, cada vez mais, esta questão foi ficando clara. Eu meapeguei muito à pergunta geradora. Ela "éo meu chão"... o chão em que eu fiz a releiturafoi o chão do PIE - das discussões do curso, dos estudos realizados para que eu possa ter um norte... Era com esse ol har que teríamos que produzir.

A intenção dessa pergunta foi colocar o professor-aluno frente a frente com suas reflexões pessoais (M iranda, 2006).

\section{D esenvolvendo estratégias para a releitura}

A releitura de portfólios permitiu enxergar uma trama de relações que, muitas vezes, pela dinâmica cotidiana, permanecia oculta e/ou silenciada. V ários procedimentos foram desenvolvidos. 
Professor-aluno - Eu fiz uma releitura para identificar al go que fizesseparte de minha reflexão pessoal quefosse próximo da minha realidade... À medida que vocêvai relendo vocêpercebeelementos que mantêm uma relação, vínculos, aí vocêsintetiza... Q uando fui reler, é que percebi que o que estava mais próximo era a questão do respeito. À medida quefui escrevendo o tcc eu precisei voltar nos fascículos para "pescar" a questão do respeito evalidar aquilo queeu estava escrevendo. Feito isso, voltei nos portfóliose en contrei textos inteiros que serviam para o meu Tcc. Eram textosque serviam para o meu tema.

Professor-aluno - N a produção do portfólio do sexto módulo, as releituras estiveram nas reflexões sobre cada fascículo. Eu estudava os fascículos, discutia em sala e, durante o registro das reflexões, eu revia como era antes. Ia anotando e destacava o que era interessante para a nova reflexão.

Professor-aluno - No último semestrefoi interessante, pois a gente começou a discutir em grupo. Às vezes tinha um colega que estava com dificuldades em al gumas coisas, aí eu já tinha desenvolvido esta prática em sala... nós trocávamos idéias, inclusive sobre o que estávamos escrevendo no portfólio, bem como no TCc... A mediadora fui muito importante também. A todo momento elaintervinha.

Em resumo, os principais procedimentos usados para a construção da releitura para a elaboração do Tcc foram: compreender a releitura na perspectiva do curSO PIE; reler o portfólio para identificar algo significativo; identificar nós/vínculos que marcam a produção pessoal do professor-aluno, gerando, assim, um tema; identificar discussões proporcionadas pelo curso para que este tema estivesse em questão no portfólio; revisitar produções nos portfólios que tivessem iniciado a discussão do tema, em busca de lacunas ou textos elaborados anteriormente; ampliar o tema em destaque com base nos estudos que foram organizados no módulo vı, bem como em outros módulos; discutir seus achados em grupo, de forma que houvesse cooperação entre os colegas de sala e entre o professor-aluno e o professor mediador.

A releitura criou clima de desenvolvimento de autoria de aprendizagens, integrando o professor-aluno na prática pedagógica, no seio da qual ele não se anulasse ( $\mathrm{H}$ adji, 2001). A todo o momento ele foi chamado a pensar sobre a sua produção. Para que isso acontecesse, a professora-mediadora desenvolveu alternativas de orientação.

N o meu caderno de registro, eu escrevi a forma como eu apresentei ao grupo de professores-mediadores, em coordenação pedagógica, como eu encaminhei a construção da releitura. Primeiro fizemos releitura dos princípiose 
descritores de avaliação do portfólio - este era um sentido mais amplo de releitura. Eu sempre procurei o que seria diferente na releitura no PIE ea diferença era o sujeito. M esmo porque a gente tinha o objetivo delevantar elementos dos portfólios que auxiliassem no Tcc.

(...) 0 que elesentendiam sobre releitura? Releituraera olhar, rever, pensar (...).

(...) Lemos e discutimos a primeira e a segunda carta de Paulo Freire, do livro Professora sim, tia não!. D epois desenvolvemos um trabal ho com a música A lista, do $\mathrm{O}$ swaldo M ontenegro. Fui coordenando a discussão para que nós discutíssemos o re-ol har ea releitura.

(...) N o grupo cada professor-aluno fez a releitura de um portfólio, pois eles estavam se perguntando o que era releitura. Então, eu disse: "Vamos exercitar as possibilidades!" Eles socializaram esaiu releitura do portfólio todo, de um texto, do eixo - como el e estava integrando as áreas e as dimensões formadoras - ereleitura de uma atividade - como faria esta atividade hoje?

(...) 0 rientei que, na releitura, eles teriam que identificar aquilo que estava muito presenteno portfólio. Era aquilo queestava se destacando ou aquilo que el evia como importante hoje eque, de repente, silenciou. A pergunta seria: "Por quesilenciou?" Era a hora de buscar isso. Poderia ser algo que estava oculto na produção.

\section{Colocando a metacognição em ação}

Para que se desenvolvam procedimentos metacognitivos em sala de aula, Grangeat (1999, p. 116) percebe a necessidade de: se reconsiderarem as práticas de avaliação; se criarem espaços de diferenciação pedagógica "na progressão ordinária", isto é, nas atividades do dia-a-dia; e se integrarem "no seio da aula momentos de reflexão sobre as aprendizagens". No processo de releitura de portfólios constatou-se a presença dos elementos acima. E mais: percebeu-se que não são isolados, mas se complementam. 0 uso do portfólio como principal procedimento avaliativo da aprendizagem dos professores-alunos representou reconsideração das práticas avaliativas: abandono da avaliação classificatória e adoção da formativa. Esse procedimento propiciou ao professor-aluno refletir sobre as produções realizadas. Assim, ele avaliava, ao mesmo tempo, o seu desempenho e o trabalho pedagógico do curso. Esse processo possibilitava a compreensão de que menções eram atribuídas simplesmente em cumprimento a normas regimentais da UN B. 0 mais importante era a aprendizagem evidenciada por cada um deles. Com o passar do tempo, observou-se 
que a preocupação inicial com a comparação de menções cedeu lugar ao entendimento de que cada sujeito tem a sua maneira de aprender e de demonstrar os resultados da sua aprendizagem.

Pensar em releitura de portfólio e desenvolvimento metacognitivo é colocar em destaque a relação do sujeito com o saber. 0 potencial da releitura de portfólio no processo de avaliação de uma tarefa desenvolvida é evidenciado nos depoimentos de professores-alunos:

A gentetem sempreque ficar refletindo o tempo inteiro, não tem como, tem que refletir sobrenossa práxis, tem que parar mesmo e pensar se real menteé aquilo e, senão é, o que poderiater sido feito de diferente.

$\mathrm{N}$ a releitura eu via que tinha mais al guma coisa para ser feita. $Q$ uando relia uma atividade feita anteriormente, eu dizia: "N ossa! Faltou. Fal tou al guma coisa, que vai ajudar mais ainda e eu vou implementar, vou acrescentar". $\mathrm{N}$ ão ficava só naquilo, era uma vi são de futuro. D o que deu certo e do que não deu. Às vezes eu via e dizia: "Isso aqui poderia ter sido melhor. N a próxima vez eu vou melhorar. Isso servia de base para aquilo. 0 quefoi bom e quais os pontos negativos queeu posso melhorar?".

A releitura de portfólios foi um revitalizador do olhar reflexivo do sujeito sobre sua produção/ação, que pode ter se perdido no decorrer do processo ou não ter sido por ele percebido em sua trajetória. Esse entendimento está retratado no seguinte depoimento:

Todo trabal ho, todos os questionamentos que eu faço, também, nascem da minha prática de sala de aula, com as experiências que eu tenho com as minhas crianças e eu percebo o seguinte: é como se, de repente, eu começasse a amadurecer um pouco mais nesse sentido, porque al go que para mim existia no campo das idéias, da crítica, de uma possibilidade de uma construção futura, eu comecei a sentir a necessidade de que ela fizesse parte da minha prática naquele momento. Q uando eu comecei a investigar essa questão do respeito de uma forma mais profunda, isso se tornou mais próximo da minha realidade.

Para Grangeat (1999, p. 121) a diferenciação pedagógica é um conceito existente há muito tempo. Ele considera a necessidade de se ultrapassar a estrita conexão entre avaliação diagnóstica e encaminhamento dos alunos que necessitam de apoio para diferentes locais e modalidades de trabalho. Trata-se, ao contrário, de criar "espaços de derivação provisória" que permitam a cada aluno "orientar-se ou ser desviado para as suas necessidades perante um dado objetivo preciso e singular". 0 autor defende a idéia 
de integração dos alunos para atendimento às diferenças e não de seu isolamento. Tanto o trabalho com o portfólio quanto o processo de releitura dos mesmos colocou em prática esse entendimento de diferenciação pedagógica. As atividades em equipe e os momentos de socialização das reflexões e das produções constituíram espaços privilegiados de diferenciação pedagógica. Os depoimentos abaixo esclarecem o processo realizado.

A mediadora fez uma estratégia muito bacana. Ela dividiu a turma em grupos, mesmo que os grupos não tivessem idéias afins, mas ela nos colocou próximos. Tinha aquele atendimento individual izado, mas o fato de estarmos em grupo fazia com que uma lesse 0 trabal ho da outra. Eu tive colega que o tema dela não era muito concreto e aí, no grupo, nós líamos e fazíamos questionamentos para ver seisso setornava claro para ela.

A mediadora colocava a opinião dela e o grupo de que eu fazia parte ouvia a intervenção e discutia, juntamente comigo, as diferentes opiniôes. A mediadora jamais impunha a sua opinião. Ela intervinha, olhava eia acrescentando o que, nos próximos textos, eu poderia acrescentar.

\section{Apresentando reflexões finais}

A pesquisa cujos resultados foram apresentados neste texto possibilitou a formulação das reflexões que se seguem.

Em primeiro lugar, percebeu-se que a avaliação teve destaque durante todo o curso e, talvez por isso, o tenha tornado único. 0 trabalho com o portfólio muito contribuiu para que isso acontecesse. D esde o início tomou-se cuidado para que ele não fosse entendido como uma pasta em que se arquivam textos. A reflexão crítica foi decisiva para a formulação dessa compreensão. A releitura reforçou esse entendimento. 0 trabal ho com o portfólio em um curso que formou dois mil pedagogos, associado à sua releitura, foi pioneiro e inovador.

Em segundo lugar, foi de inestimável relevância a construção coletiva do processo de releitura, envolvendo todos os professores-mediadores, que formularam, em conjunto, as suas diretrizes, e os professores-alunos que, junto com os primeiros, as analisaram, colocaram em prática e fizeram as necessárias alterações.

Em terceiro lugar, a releitura para a construção do TCc possibilitou repensar todo o processo de formaçãa. Cada professor-aluno pôde associar os estudos teóricos e as atividades do curso ao contexto de sua atuação 
como docente de escola pública do Distrito Federal. Os mecanismos de diferenciação pedagógica (atividades em equipe, análise dos portfólios, socialização dos portfólios, apresentação oral de reflexões feitas individualmente, articulação dos estudos realizados no curso com as atividades desenvolvidas nas escolas em que atuavam os professores-alunos etc.) contribuíram para que isso acontecesse. A padronização do trabalho pedagógico foi substituída por atividades que incorporaram diferentes linguagens. Contudo, essa não foi uma tarefa fácil.

Em quarto lugar, a releitura possibilitou o desenvolvimento metacognitivo, ao incentivar, por um lado, a reflexão e a crítica pessoal e, por outro, 0 trabalho em equipe e a troca de idéas. Levou-se em conta que

(...) a metacognição éuma reflexão interior do sujeito, sendo inacessível ao observador em condições habituais deensino. C omo qualquer atividade mental, ela tem de ser inferida, seja a partir do que o sujeito diz dela, seja a partir do que elefaz ao resolver, por exemplo, um problema. (Grangeat, 1999, p. 99)

Em quinto lugar, cabe destacar que o trabalho com o portfólio, associado à sua releitura, e o desenvolvimento metacognitivo representam grandes possibilidades no processo de formação de professores. Porém, é preciso mais. Há a necessidade de investigação que acompanhe os sujeitos na construção dos seus portfólios e no processo de releitura, para que se conheça com detalhes como esse desenvolvimento ocorre.

Recebido em janeiro de 2007 e aprovado em julho de 2007.

\section{Referências}

ESTEBAN, M .T.; ZACCUR, E. A pesquisa como eixo da formação docente. In: Esteban, M.T.; Zaccur, E. (O rg.). Professora-pesqui sadora: uma práxis em construção. Rio de Janeiro: DP\&A, 2002. p. 15-31.

FERREIRA, A.B.H. N ovo Aurélio Século xxI: 0 dicionário da língua portuguesa. 3. ed. Rio de Janeiro: N ova Fronteira, 1999. p. 1325.

GRAN GEAT, M . A metacognição, um desafio à autonomização. In GrANGEAT, M . (Coord.). A metacogni ção, um apoio ao trabalho dos alunos. Portugal: Porto, 1999. 
H ADJI, C. Avaliação desmistificada. Porto Alegre: ARTM ED, 2001.

M IRAN D A, C.Q . A releitura de porta-fólios para a construção do Trabalho de Conclusão de Curso de Pedagogia. 2006. 180p. Tese (mestrado) - Faculdade de Educação da Universidade de Braślia, Braślia.

RIBEIRO, C. M etacognição: um apoio ao processo de aprendizagem. Psicologia: reflexão e crítica, Porto Alegre, v. 16, n. 1, p. 109-116, 2003.

UN B. Faculdade de Educação. Curso de Pedagogia para professores em exercício no início da escolarização - Projeto, 1999.

UN B. Faculdade de Educação. M ódulo vi - PIE. 2003.

VILLAS BO AS, B.M .F. Portfólio, avaliação e trabalho pedagógico. Campinas: Papirus, 2004. 